$\underline{\text { Article }}$

\title{
MNE Opportunities to Lead Global Sustainable Development through Food Waste Recycling
}

\author{
Sarah $\mathrm{Ku}^{1} \odot \otimes$ \\ 1 Georgia State University, USA \\ Keywords: food waste, multinational enterprises, waste management, recycling \\ https://doi.org/10.46697/001c.32991
}

\section{AIB Insights}

Vol. 22, Issue 1, 2022

\begin{abstract}
Food waste is a global problem. When discarded into landfills through traditional municipal solid waste disposal, food waste is costly, contributes to greenhouse gas emissions, and highlights disparities of food insecurity. Government and retail campaigns overwhelmingly target consumers as responsible actors for tackling food waste through prevention, reduction, and recovery activities. Multinational enterprises (MNEs), however, play significant roles in contributing to global food waste and therefore must also face responsibility for contributing to sustainable solutions. The organizational management of food waste through recycling strategies confronts multiple United Nations Sustainability Development Goals (SDGs) with economic, environmental, and social implications.
\end{abstract}

\section{INTRODUCTION}

We routinely waste one-third of the food we produce in this world. Annually, this waste costs $\$ 940$ billion USD and represents $8 \%$ of greenhouse gas emissions; meanwhile, over 800 million people suffer from hunger and malnutrition (Food and Agriculture Organization of the United Nations, 2017; Hanson \& Mitchell, 2017). These statistics reveal significant economic, environmental, and social challenges. Most food waste is discarded through municipal solid waste streams into landfills, which is costly to transport and store, detrimental to the environment due to transportation carbon footprints and methane produced from landfills, and further marginalizes populations that incur the air, water, and ground contamination caused by this disposal method. Despite being the most common destination for food waste, landfills are the last place food waste should go based on widely accepted food waste hierarchies (Dubbeling, Bucatariu, Santini, Vogt, \& Eisenbeiß, 2016; US EPA, 2015). These hierarchies first prioritize activities focusing on prevention and reduction, then recovery for human consumption, then recycling for non-human-consumption purposes, with landfilling as a last resort.

Despite this tiered ranking, recycling food waste has the potential to divert larger volumes of waste away from landfills, create more jobs, and contribute greater economic value than prevention, reduction, and recovery activities combined (ReFED, 2016), as shown in Table 1. In many cases, food waste is unavoidable even with lean operation strategies, and issues of contamination, safety, and edibility complicate recovery efforts for donations to those in need. However, food waste has nutrients, calories, cellulose, etc. that are valuable for alternative applications. The land, water, fertilizer, and labor used to produce food must also be considered when measuring this waste product. When in- tegrating these factors, the intrinsic value of this material reveals vast potential for untapped markets. Preventing, reducing, and recovering food waste are important and should remain high priorities, but recycling this resource is often skipped over completely, with food waste most commonly going directly to landfills before exploring recycling options. Recycling encompasses a variety of activities, such as repurposing for animal feed, compost for fertilizer and soil amendment, energy, and feedstock for manufacturing. When produced sustainably, food and its subsequent waste is a renewable, abundant, and constant resource. Recycling food waste offers market opportunities for a universal externality that remains largely underexplored in business research and underleveraged in business practice.

The United Nations Sustainability Development Goals (SDGs) encompass 17 goals and 169 targets, which are meant to provide blueprints to reach sustainable development advancements by 2030, an imminent deadline. These goals are expansive, which can result in paralysis of action. While an all-encompassing "silver bullet" solution is unrealistic, some actions combat multiple SDGs simultaneously for greater impact. Managing food waste through recycling strategies confronts several SDGs, including, but not limited to, Responsible Consumption and Production (SDG 12); Climate Action (SDG 13); Zero Hunger (SDG 2); Sustainable Cities and Communities (SDG 11); Industry, Innovation, and Infrastructure (SDG 9); Decent Work and Economic Growth (SDG 8); Life on Land (SDG 15); Good Health and Well-Being (SDG 3); and Partnerships for the Goals (SDG 17).

Historically, governments and retailers facilitate food waste reduction campaigns that target consumers, but these efforts mainly focus on increasing awareness and educating consumers to nudge individual behavioral changes. While these campaigns are important, they are limited in scope because of their narrow concentration on consumer 
Table 1. Annual estimations of economic, environmental, and societal impacts of food waste activities

\begin{tabular}{ccccc}
\hline Activity category & $\begin{array}{c}\text { Diversion potential } \\
\text { Volume in million tons }\end{array}$ & $\begin{array}{c}\text { Economic value } \\
\text { USD in billions }\end{array}$ & $\begin{array}{c}\text { GHGs reduced } \\
\text { In million tons of } \mathrm{CO}_{2}\end{array}$ & $\begin{array}{c}\text { Jobs created } \\
\text { In thousands }\end{array}$ \\
\hline Prevention / Reduction & 2.6 & $\$ 7.7$ & 9.7 & - \\
Recovery & 1.1 & $\$ 2.4$ & 3.4 & 4 \\
Recycling & 9.5 & $\$ 121$ & 4.8 & 11 \\
\hline
\end{tabular}

Source of data: ReFED, 2016

populations. Corporate managers have captive employee audiences and can leverage internal management and marketing strategies to influence employee behavior within their own organizational walls. Researchers and managers have much to gain from cooperative collaborations to develop knowledge to collectively solve problems (Bansal \& Sharma, 2021).

We seek to bridge academia and industry by contributing two main insights. First, we describe the landscape of food waste in multinational enterprises (MNEs) to critically examine their role and responsibility to sustainable development. Second, we describe tangible, actionable strategies for MNEs to leverage food waste for economic, environmental, and social advancements to address multiple SDGs. We regularly assume that corporate changes surrounding SDGs require regulatory carrots (i.e., incentives) or sticks (i.e., mandates) through public policies. Utilizing waste as a resource is increasingly urgent for corporate, ecological, and societal survival and offers opportunities to reduce supply chain vulnerabilities, create new markets, and create jobs without further degrading the planet. These contributions provide implications for managers and policymakers to direct more attention to MNEs to tackle SDGs through organizational food waste recycling.

\section{THE ROLE AND RESPONSIBILITY OF MNES ON FOOD WASTE}

SDGs encourage and require involvement from multiple stakeholders, not least of which includes the private sector. Paradoxically, corporations receive inconsistent accountability for contributing to global problems and bearing responsibility for their solutions (Hahn, Kolk, \& Winn, 2010). Broadly defined, MNEs produce goods and/or deliver services in more than one country. MNEs are responsible for approximately one-third of global production, half of global exports, one-third of world GDP, and one-fourth of global employment (OECD, 2018), thus demonstrating substantial contributions to international business and economic globalization. They also represent high concentrations of material and intellectual capital, resource sharing, and centralized management systems. These features enable MNEs to confront SDGs through their own organizational strategies, operations, and cultures. Since MNEs operate in various geographic regions with access to many individuals and resources, MNEs are uniquely positioned, compared to domestic firms, to tackle food waste with broader reach for greater global impact.

Given the international scope, employment, resources, financial investments, and infrastructure of MNEs, they represent essential actors for global food waste initiatives. Industrial, organizational, and residential sectors represent $39 \%$, $37 \%$, and $24 \%$, respectively, of estimated annual food waste generation (United States Environmental Protection Agency, 2020). The residential sector receives disproportionate attention in research and policies despite being the smallest sector responsible for food waste generation. Global trends indicate that individuals frequently eat at their place of work (Lin et al., 2017), revealing opportunities for organizations to reflect on their own operations and strategies to tackle food waste.

Undoubtedly, "the role of MNEs is without dispute; not least because they have actively collaborated in the formulation of the SDGs themselves" (van Zanten \& van Tulder, 2018: 25). Therefore, the question of whether or not MNEs should play a role in achieving SDGs is not the proper framing. The more appropriate question is how should MNEs address SDGs? The SDGs are overwhelming for any single institution to grasp. Instead, SDGs require creative collaborations from public, private, and individual actors to tackle multiple issues simultaneously. Yet, corporate actors (e.g., MNEs) continue to receive unbalanced attention in their role and responsibility to participate in these collaborative solutions for global advancements (Hahn et al., 2010).

Top-down approaches from government institutions have wide reach but are cumbersome and slow to execute. Bottom-up approaches from individuals are marginal in scale and difficult to coordinate. By focusing on agile lower order systems of individual employees and managers within organizations, MNEs can adopt strategies more quickly than through top-down or bottom-up approaches. MNEs have the ability, control, and responsibility to influence behaviors within their own organizational boundaries. Not all consumers of food are employees of MNEs, but all MNE employees consume food. MNEs can either be proactive leaders, stagnant bystanders, or reactive laggards in addressing SDGs, with consumers and investors increasingly monitoring these strategies. Proactive MNEs have first-to-market competitive advantages with heightened goodwill and reputational implications. Millennial and Gen Z workers expect their employers to actively engage in environmental and social issues, such as offering opportunities for employees to participate, which are trends that continue to grow. Inactive MNEs continue status quo operations despite a necessary shift to find alternatives to nonrenewable resources for feedstock and energy. Reactive MNEs wait until forced into regulated compliance and may incur financial fees, operational mandates, and/or brand abandonment in a world in 
Table 2. Examples of outcomes of various food waste recycling activities for MNEs (neither exhaustive nor exclusive)

\begin{tabular}{|c|c|c|c|}
\hline \multirow{2}{*}{$\begin{array}{l}\text { Recycling } \\
\text { activity }\end{array}$} & \multicolumn{3}{|c|}{ Outcomes } \\
\hline & Economic $^{1}$ & Environmental $^{2}$ & Social $^{3}$ \\
\hline $\begin{array}{l}\text { Animal } \\
\text { feed }\end{array}$ & $\begin{array}{l}\text { Reduces costs for } \\
\text { excess feed }\end{array}$ & $\begin{array}{l}\text { Reduces land, water, and carbon } \\
\text { footprints from producing excess } \\
\text { feed }\end{array}$ & $\begin{array}{l}\text { Promotes food security by feeding } \\
\text { livestock for human consumption }\end{array}$ \\
\hline Compost & $\begin{array}{l}\text { Reduces fertilizer costs } \\
\text { for landscaping }\end{array}$ & $\begin{array}{l}\text { Produces fertilizer, amends soil, } \\
\text { sequesters carbon }\end{array}$ & $\begin{array}{l}\text { Promotes food security by growing food } \\
\text { from compost }\end{array}$ \\
\hline $\begin{array}{l}\text { Anaerobic } \\
\text { digestion }\end{array}$ & $\begin{array}{l}\text { Reduces costs for } \\
\text { nonrenewable energy }\end{array}$ & $\begin{array}{l}\text { Produces renewable energy, } \\
\text { produces fertilizer }\end{array}$ & $\begin{array}{c}\text { Produces renewable energy, promotes } \\
\text { food security by growing food from } \\
\text { compost }\end{array}$ \\
\hline $\begin{array}{l}\text { Feedstock for } \\
\text { manufacturing }\end{array}$ & $\begin{array}{l}\text { Reduces supply chain } \\
\text { vulnerabilities / } \\
\text { dependencies }\end{array}$ & $\begin{array}{l}\text { Produces renewable non-virgin } \\
\text { feedstock material }\end{array}$ & $\begin{array}{c}\text { Stimulates innovation for creative } \\
\text { products }\end{array}$ \\
\hline Biofuel & $\begin{array}{l}\text { Reduces costs for } \\
\text { nonrenewable energy }\end{array}$ & Produces renewable energy & $\begin{array}{l}\text { Produces biosoap for improved health } \\
\text { and well-being }\end{array}$ \\
\hline
\end{tabular}

\footnotetext{
${ }^{1}$ Recycling activities reduce varying amounts of economic cost savings (e.g., landfill tipping fees, fuel costs) as well as value added products that can be sold for positive returns on investment

${ }^{2}$ Recycling activities reduce varying amounts of greenhouse gas emissions (e.g., $\mathrm{CO}_{2}$ from transportation, methane from landfills)

${ }^{3}$ Recycling activities create varying numbers of jobs, both internal and external, through logistics and management of food waste (e.g., creating and operating gardens to grow food

for employees, managers, and community members)
}

which consumers and investors signal values through their purchases and economic activity.

Strategies that can be implemented throughout a company with relatively little help from the government or civil society are easier for MNEs to execute given high levels of autonomy and control for self-regulation (van Zanten \& van Tulder, 2018). MNEs implement a variety of tactics when it comes to SDGs, ranging from launching their own initiatives to conforming to mandated regulations and norms. Food waste is a universal, inevitable, and renewable corporate externality that offers unique opportunities for MNEs to voluntarily lead in valorizing and commodifying this resource instead of discarding it. MNEs can, should, and must be leaders in global sustainable development, and one way to achieve this is through food waste recycling activities.

\section{OPPORTUNITIES FOR MNE FOOD WASTE}

Recycling food waste presents numerous actionable opportunities, some of which are outlined in Table 2. This Table is not meant to be exhaustive or exclusive, but rather illustrates tangible activities that MNEs can implement to address multiple SDGs. These recycling activities can be incorporated into the waste management operations of any organization - small or large, domestic or foreign - through internal or external strategies. However, MNEs have flexibility to determine which activities best fit their industry, infrastructure, physical space, capital investment, volumes, etc. MNEs have unique reach and resources that position them well to be leaders in shifting operational norms for international business that promotes sustainable development. We describe these activities in further detail below.

Recycling food waste for animal feed is a practical strategy in rural areas when MNEs have proximity to livestock operations and facilities that process pet food. A growing global tactic involves using insects (e.g., black soldier fly larvae, cockroaches) to process food waste. Not only do insects naturally and rapidly consume food waste, but they can also then be utilized for human consumption, as more animal feed, in medicinal applications, for compost, or converted into energy. Composting transforms food waste into nutrient-rich fertilizer and soil amendments by combining it with other organic materials (e.g., dried leaves, yard waste), heat, water, aeration, and time. Composting systems range from small indoor bins (e.g., vermicomposting) to large-scale industrial operations (e.g., aerated static piles, windrow) and vary in terms of physical size, processing capacity, and time frames to reach a finished product. Anaerobic digestion employs microorganisms that break down food waste in the absence of oxygen to produce methane in a controlled procedure to harness energy (e.g., biogas, electricity, heat). Combining food waste with other types of waste (e.g., animal manure, wastewater biosolids) may result in higher yields of energy depending on the capabilities of the digestor. This process also produces nutrient-rich fertilizer as a byproduct.

The disparities between food waste and hungry people highlights problems of logistics, not production capacity. Producing food in food deserts that have less resources, land, equipment, and funding are necessary to increase $a c$ cess to food. Compost can be used in plot gardening and vertical farming to increase food security in urban settings with limited physical space. Feeding food waste to insects to then be used as fish feed in aquaponics systems offers another non-traditional agricultural technique for producing food in situations with spatial constraints. Community gardens frequently rely on support from nonprofits, government grants, and community volunteers. MNEs facilitate infrastructures (e.g., buildings, roads) and employ workers located in food deserts around the world. Sometimes em- 
ployees cannot afford healthy food or do not have easy access to it while juggling work, transit, and family schedules. By recycling food waste and creating corporate / community gardens, MNEs can activate their role and responsibility to contribute to increasing food security and well-being for their employees and their communities.

Commodifying food waste into feedstock for manufacturing upcycles this material into new products of higher value. A firm in Italy recycles orange peels into fiber for fabric. A German firm compresses coffee grounds with plant fibers, beechwood grains, and natural resins to create biodegradable coffee cups. A firm in Micronesia converts banana leaves into wallets and business cards. Combining crab shells with tree fibers may one day replace flexible plastic packaging. Food waste in the form of fats, oils, and grease are converted into biodiesel, generating a source for renewable energy. This process also yields useful byproducts (e.g., soap) offering an alternative to palm oil, which contributes substantially to deforestation and climate change.

One way MNEs can recycle food waste is to outsource activities (external action) by selling their food waste to other firms to process. Alternatively, MNEs can vertically integrate food waste recycling (internal action) into their own operations. Both strategies promote circular design to reincorporate waste back into economies instead of linearly discarding it. Outsourcing these activities creates more external jobs but likely requires more shipment of this material, which is not without consequences. Vertically integrating these activities creates more internal jobs with tighter systems of circularity. Regardless of the strategy, efficient resource utilization of food waste has significant potential to reduce costs, greenhouse gas emissions, and the marginalization of food insecure populations. Empirical research on food waste recycling activities in MNE contexts would provide valuable developments to quantify and qualify which activities have the greatest impact on various economic, environmental, and social dimensions.

Some MNEs have employee programs that incentivize or mandate employee involvement in SDG initiatives, such as spending one hour per month on sustainable development projects (e.g., distributing educational materials, designing training content, building houses). Food waste recycling offers tangible opportunities for managers and employees of MNEs to directly tackle several SDGs. Considerable differences (e.g., costs, technical expertise, infrastructure, physical space) between these activities present limitations based on the specific MNE. The optimal solution will vary depending on an MNE's capabilities and desired outcomes. MNEs should be mindful to apply customized strategies for countries with different cultural norms, regulatory restrictions, and geographic constraints the same way they conduct market segmentation. Combining activities and trying creative innovations may maximize opportunities for resource efficiencies and new markets. Future research that explores how and why MNEs manage food waste would provide important contributions to identify and understand the drivers and barriers of these activities for sustainable development in international business.

\section{CONCLUSION}

MNEs can, should, and must be leaders in global sustainable development. One way they can tackle multiple SDGs simultaneously is by treating food waste as a valuable resource. Whether this resource is sold as a commodity or processed through in-house operations, recycling food waste offers opportunities for economic, environmental, and social advancements. By utilizing the full potential of food waste from a managerial perspective, MNEs can reduce supply chain vulnerabilities, negative impacts on the environment, and food insecurity for their employees and communities. From a policymaker standpoint, positioning public policies to support MNE leadership for sustainable development stimulates public-private collaborations (SDG 17). These public-private collaborations could manifest as policies that support MNE activities through subsidies for diverting food waste away from landfills through circular activities and through employee-community garden partnerships to reduce food deserts and insecurity. Business research surrounding food waste pays limited attention to MNE contexts despite significant opportunities for theoretical development on profitable strategies that concurrently benefit the environment and society. We offer insights that encourage managers and policymakers to leverage food waste in a time when resource depletion, climate change, and social disparities threaten international business indiscriminately. We contribute a variety of specific, actionable activities for MNE managers and policymakers to confront SDGs by managing organizational food waste efficiently. These insights also highlight important areas for growth in research and education to bridge academia and industry for relevant theoretical and practical developments. MNEs play a critical role in driving firm-level innovations to address multiple SDGs through food waste recycling and must be held accountable to realize their leadership for sustainable development.

\section{ACKNOWLEDGEMENTS}

I am grateful for Editor John Dilyard and two anonymous peer reviewers for their constructive, timely, and supportive feedback. I also thank S. Tamer Cavusgil and Leigh Anne Liu for their continuous guidance and encouragement during the initial stages of research leading to this paper.

\section{ABOUT THE AUTHOR}

Sarah Ku (https://www.sarahku.com) is a $\mathrm{PhD}$ candidate at Georgia State University. She will join Loyola University Chicago as a tenure-track Assistant Professor of Sustainable Business Management in August 2022. Her research areas include sustainability, equity, circular strategies, and biomimicry in business. She has been involved with the AIB Sustainability shared interest group since its inception as a founding member of the "Circular Economy in an IB Context" thematic group and became an Officer of its Working Committee in 2021. 
Submitted: September 14, 2021 EST, Accepted: February 15, mons.org/licenses/by/4.0/legalcode for more information. 


\section{REFERENCES}

Bansal, P., \& Sharma, G. 2021. Three Different Approaches to Impact: Translating, Cocreating, and Performing. Business and Society, 1-6.

Dubbeling, M., Bucatariu, C., Santini, G., Vogt, C., \& Eisenbeiß, K. 2016. City Region Food Systems and Food Waste Management: Linking Urban and Rural Areas for Sustainable and Resilient Development. Deutsche Gesellschaft für Internationale Zusammenarbeit (GIZ) GmbH. https://www.fao.org/3/ i6233e/i6233e.pdf.

Food and Agriculture Organization of the United Nations. 2017. Global Initiative on Food Loss and Waste. https://www.fao.org/3/i7657e/i7657e.pdf.

Hahn, T., Kolk, A., \& Winn, M. 2010. A new future for business? Rethinking management theory and business strategy. Business \& Society Society, 49(3): 385-401.

Hanson, C., \& Mitchell, P. 2017. The Business Case for Reducing Food Loss and Waste. In Champions 12.3. https://champions123.org/wp-content/uploads/ 2019/02/Report The-Business-Case-for-Reducing-Fo od-Loss-and-Waste_Restaurants.pdf.

Lin, L., Nasaw, D., Turner, Z., Houston-Waesch, M., Koh, Y., et al. 2017. How the World Eats Lunch. Wall Street Journal. https://www.wsj.com/articles/how-th e-world-eats-lunch-1496154663.
OECD. 2018. Multinational enterprises in the global economy: Heavily debated but hardly measured. OECD, May 2018. https://www.oecd.org/industry/ind/ MNEs-in-the-global-economy-policy-note.pdf.

ReFED. 2016. A Roadmap to Reduce U.S. Food Waste by 20 Percent - Foundation Action Guide. https://sta ging.refed.org/downloads/Foundation_Action_Pape r Web.pdf.

United States Environmental Protection Agency. 2020. 2018 Wasted Food Report: Estimates of generation and management of wasted food in the United States in 2018. Office of Resource

Conservation and Recovery: EPA 530-R-20-004, November 2020. https://www.epa.gov/sites/productio n/files/2020-11/documents/2018 wasted food repor t.pdf.

US EPA. 2015. Food Recovery Hierarchy. https://ww w.epa.gov/sustainable-management-food/food-recov ery-hierarchy.

van Zanten, J. A., \& van Tulder, R. 2018.

Multinational enterprises and the sustainability development goals: An institutional approach to corporate engagement. Journal of International Business Policy, 1(3-4): 208-233. 